\title{
Topics
}

Jia Wang*

\section{Do Economic Development Incentives Crowd Out Public Expenditures in U.S. States?}

DOI 10.1515/bejeap-2015-0042

Submitted November 8, 2015; published online November 27, 2015

Abstract: This paper investigates whether economic development incentives (EDI) crowd out public expenditures in U.S. states. Using EDI data from a new database, this paper employs a two-way fixed effect panel framework and generalized method of moments (GMM) approach to account for dynamic features associated with public expenditures. Potential endogeneity of policy variables and problems with unbalanced panels are also addressed. Results show relatively little effect of incentives spending on most public goods expenditures contemporaneously, with negative repercussions beginning to appear in year one. Findings of this paper carry practical importance for policymakers concerning the efficacy of incentives.

Keywords: economic development incentives, public goods provision, state and local governments

JEL Codes: H41, H71, H72

\section{Introduction}

"Economic development incentives waste a lot of money on a microscopic fraction of employees and states should focus on investing in infrastructure and education that benefit everyone, rather than showering big companies with dollars." - Greg LeRoy ${ }^{1}$

Economic development incentives (EDI), including tax and nontax instrument, are prominent in the state and local fiscal landscape in the United States. According to the New York Times, state and local governments offer more than

1 Greg LeRoy, head of Good Jobs First, an economic development watchdog group, who was concerned about extensive offers of incentives to companies. "Sweet land of subsidy": http:// www.economist.com/news/united-states/21576669-downturn-has-forced-states-be-savvier-andmore-careful-about-providing-tax..

*Corresponding author: Jia Wang, Department of Economics, University of the South, Sewanee, TN, USA, E-mail: jiwang@sewanee.edu, wangjia1029@gmail.com 
$\$ 80$ billion in incentives each year. Recipients come from a variety of industries: oil and gas, technology, entertainment, financial services and retailers. More than $\$ 1$ million worth of incentives has been awarded to some 5,000 companies. Notably, these incentive offers account for a substantial portion of the overall spending in many communities.

The worry that EDI may crowd out resources for productive public goods such as education and infrastructure is not new (Bartik 1994; Burstein and Rolnick 1995; Wilson 1999; Gorin 2008; Kenyon, Langley, and Paquin 2012). In 2011, states reduced public goods provision and increased taxes by an aggregate of $\$ 156$ billion according to the Center on Budget and Policy Priorities. Despite the extensive EDI literature, however, few studies focus on this aspect. Two notable exceptions are Greenstone and Moretti (2003), and Patrick (2012), both of which examine the effects on county finances following the opening of a large plant ("Million Dollar Plant"). This paper extends the literature by examining the effect of EDI on the provision of public goods at the state level.

This paper contributes to existing literature in a number of important ways. First, given the widespread use of EDI, it is of paramount importance that policymakers have a better understanding of the costs of such policies. The opportunity costs in terms of forgone public goods and services have been demonstrated to be critical for a state's economic growth (Helms 1985; Mofidi and Stone 1990; Fisher 1997). Second, this study is aggregated at the state level. Previous literature has pointed out that the fiscal impacts of incentives at the state level are likely to be different from those at the local level (Peters and Fisher 2004). Hence, it is important to examine state-level tax incentives because they account for the biggest portion since the Tax Reform Act of 1986 (Luger and Bae 2005). Third, by exploiting a new and exciting national database on incentives, I explore the aforementioned question using panel data across U.S. states. My research, therefore, provides more generalizable results in contrast to previous literature which focuses on evaluating particular incentives or incentive programs in a single geographic area.

This paper empirically examines the relationship between incentives use and public expenditures using panel data for U.S. states from 1988 to 2008. System generalized method of moments (GMM) approach is used to account for dynamic features associated with public expenditures. I also use forward orthogonal deviation to transform the data for GMM estimation to mitigate the problem of magnified gaps in an unbalanced panel associated with first-differenced transformation. Additionally, the empirical model includes lags of incentives to account for lagged effects of incentives expenditures.

The GMM estimation results indicate little effect of EDI on most public goods in the current year with some negative repercussions appearing in year one. 
Increases in EDI spending (as a fraction of total public expenditures) are associated with decreases in expenditures on some categories of productive public goods (corrections, elementary education, higher education, highways, police and fire protection and sanitation) a year later. At the same time, there is evidence that incentives are associated with increases in health and human services expenditures two years later. Overall, the results of this paper lend support to the concern that EDI crowds out spending on public goods and services. Considering the critical role that productive public goods and services play in promoting state economic growth, these results serve as additional warning for policymakers who contemplate using EDI to stimulate economic growth.

The paper proceeds as follows. Section 2 surveys previous literature. Section 3 describes the state-level panel data used for the estimation, while Section 4 presents the econometric models which will be used to investigate the effect of incentives expenditures. Section 5 presents an analysis of empirical results. Robustness checks are performed in Section 6, and Section 7 concludes.

\section{Status of Literature}

There is extensive literature examining the efficacy of EDI in attracting business investments, creating jobs and stimulating economic growth. However, no consensus has been reached regarding the effectiveness of such policies (Patrick 2014). Advocates of incentives see them as an effective means for growth and claim that incentives can "pay for themselves." They argue that business decisions will be influenced by incentives, leading to job creation and growth (Greenstone and Moretti 2003). As a result, revenues from new economic activities negate the offered incentives. They also argue that the costs of incentives will be effectively lower if job creation reduces state's spending on welfare programs. Critics, however, believe that incentives are not effective at the margin, hence there is little growth induced, if any (Peters and Fisher 2004). In addition, even if higher levels of economic activity are achieved, population growth may ensue. The additional strain on crowded public goods like infrastructure, education and other services is likely to prevent the expected growth from happening (Bartik 1991). Taken as a whole, the literature is not very useful for policymakers in determining under which circumstance, if any, to offer EDI.

The lack of consensus in existing literature is attributable to differences in data and methodologies. This can be seen most prominently in case studies (Bartik and Erickcek 2012; Weiner 2009; Calcagno and Hefner 2009; Wong and Stiles 2007; Hoyt, Jepsen, and Troske 2007; Luger and Bae 2005; Goodman 2003). The myriad of case studies, however, suffer from lack of generalizability. 
Such case studies do not inform the use of EDI elsewhere due to idiosyncratic nature of programs, industries and location-specific factors.

Existing state-level studies generally find that incentives are positively correlated with state income and job growth (OhUallachain and Satterthwaite 1992; De Bartolome and Spiegel 1997; Goss and Phillips 1997). However, results based on indirect measures of incentives in earlier research may not be very meaningful (Fisher and Peters 1997).

More recent research exploits more detailed data and more advanced econometric techniques: Greenstone and Moretti (2003), and Patrick (2012) are prime examples. The former examines the effect of winning a large plant on wages, property values and public finances by using runner-up counties (i.e., the "losers") as a counterfactual for winners. They do not find any reduction in public goods provision as a result of winning the bid. Patrick (2012) uses a matching strategy to identify the effect on employment, earnings as well as the fiscal impacts of a million dollar plant opening. She finds that winning counties appear to provide an increased level of public services to their growing populations, but that service improvements are funded by borrowing rather than the creation of a fiscal surplus.

The previous literature largely neglects the issue of how EDI affects the provision of public goods and services. To my best knowledge, no study has explored the question at the state level. This question is important in that if incentives are not effective in influencing business location decisions, then using them would detract from growth by reducing funds available for spending on productive public goods and services.

Bartik (1991), Fisher (1997), and Wasylenko (1997) among others have reviewed how state and local fiscal policy in general affects growth. ${ }^{2}$ Using a budget constraint approach, Helms' (1985) seminal paper establishes that economic growth is enhanced if increased revenue through higher taxes is used to fund public goods and services such as education, highways and public health and safety; while economic growth is retarded if revenue is used to finance transfer payments. The explanation is that benefits from improved public goods and services outweigh the disincentive effects of the associated higher taxes. His findings underscore the importance of considering impacts of a state's expenditures as well as its taxes. Following Helms (1985), Mofidi and Stone (1990) reach similar findings regarding the effect on investment and manufacturing employment. They suggest that there are trade-offs in state and local tax and expenditure policies and point out that raising transfer payment at the cost of less public

2 Fisher (1997) concluded that at least "some public services clearly have a positive effect on some measures of economic development in some cases." 
investments in education, health, highways and other public infrastructure has adverse consequences.

\section{Data}

\subsection{Measures of EDI}

Existing literature establishes that ideal measures for EDI do not exist (Fisher and Peters 1997; Patrick 2014). Many earlier studies use problematic data or use measures that inadequately reflect how active governments were in offering incentives. Simple counts of incentives programs, for example, can be severely misleading and are a poor measure of a state's economic development efforts. Programs on a state's book may be outdated and states may combine or divide programs without changing the generosity of incentives offered (Fisher and Peters 1997). A state's economic development agency spending is also flawed because development agency funds can be used for noneconomic activities and EDI spending may come from alternative sources. ${ }^{3}$ Conclusions based on a measure like this are questionable.

This paper exploits the Subsidy Tracker, gathered by the nonprofit, nonpartisan group Good Jobs First, as discussed in the literature (Jansa and Gray 2014). ${ }^{4}$ This database brings together public records of incentives granted to businesses under a wide variety of state and local programs and is publicly available online. It includes the actual dollar value of incentives granted, providing a measure of state EDI spending that was previously elusive.

Subsidy Tracker is the first national search engine for EDI. It includes 12 broad categories of both tax and nontax incentive programs (tax credits/rebates, property tax abatements, megadeal, grants/low-cost loans, enterprise zones, tax increment financing, training reimbursements, cost reimbursements, infrastructure assistance, industrial revenue bonds, tax credits/rebates and grants, tax credits/rebates and property tax abatements). ${ }^{5}$ Despite extensive efforts to

3 Gorin (2008) provides an excellent example from Oklahoma. Notably, the data source for state economic development agency expenditure, i.e., the website for the National Association of State Development Agencies (NASDA), does not exist anymore.

4 Subsidy Tracker database: http://www.goodjobsfirst.org/subsidy-tracker. For detailed description of incentives types included, please refer to Subsidy Tracker user guide: http:// www.goodjobsfirst.org/subsidy-tracker-user-guide.

5 Most incentive programs, however, are concentrated in two categories: tax credits/rebates and grants/low-cost loans. Hence, it is not feasible to estimate the model for each category of incentives. 
collect information on all 50 states and D.C., this database is unlikely to be inclusive of all incentive programs and the granted values, as discussed in the literature (Kenyon, Langley, and Paquin 2012). For example, it reports EDI value for some programs in Hawaii but does not have the corresponding award year; meanwhile it documented programs in certain years for Hawaii but did not report the corresponding EDI value. Entries like this are dropped in the following analysis. Still, it is the most comprehensive database of incentives available and provides a reasonable proxy for actual overall spending. ${ }^{6}$

This paper utilizes the Subsidy Tracker database (September 10, 2013 version) and aggregates subsidy values by state-year so that each observation is the value of subsidies granted by a state in a specific year. ${ }^{7}$ Due to limited data availability of government finance data, only entries up to 2008 are included. In addition, states are dropped when EDI spending information is only available immediately before 2008 .

As a result, 29 states are included in the sample (listed in Table 9). The number of states covered varies by year. More recent years typically contain more states. On average, there are five states represented in the early 1990s, and 20 states since 1995. Sample states account for 60\% of all EDI spending and $90 \%$ of the population documented in the Subsidy Tracker database during the sample period. As shown in Figure 1, the geographic coverage of sample states is fairly spread out across the country with representation in each region.

\subsection{Other Variables}

To circumvent the problem of panel unit roots, dependent variables are different categories of state and local government expenditures as a percentage of total expenditures. ${ }^{8}$ The model is estimated using U.S. data from 1988 to 2008. State and local government finance data were provided by the Census. Population density, the proportion of population under age 15 and the proportion of population above age 65 are from the U.S. Census. The Bureau of Economic Analysis (BEA) provides data on personal income as well as consumer price

6 Harpel (2014) has a detailed discussion about Subsidy Tracker. http://www.smartincentives. org/blogs/blog/14754093-good-jobs-first-and-subsidy-tracker-2-0.

7 It is worth noting that Subsidy Tracker database does not distribute multiyear packages over award years. Rather the total package amount is recorded in the first year of the award.

8 Note that per capita government finance measures were created by first aggregating the expenditures and then dividing by population. Further, considering that crowding out effects are more likely to occur through operating expenditures, which are financed through current revenues, operating expenditures rather than capital expenditures are used. 


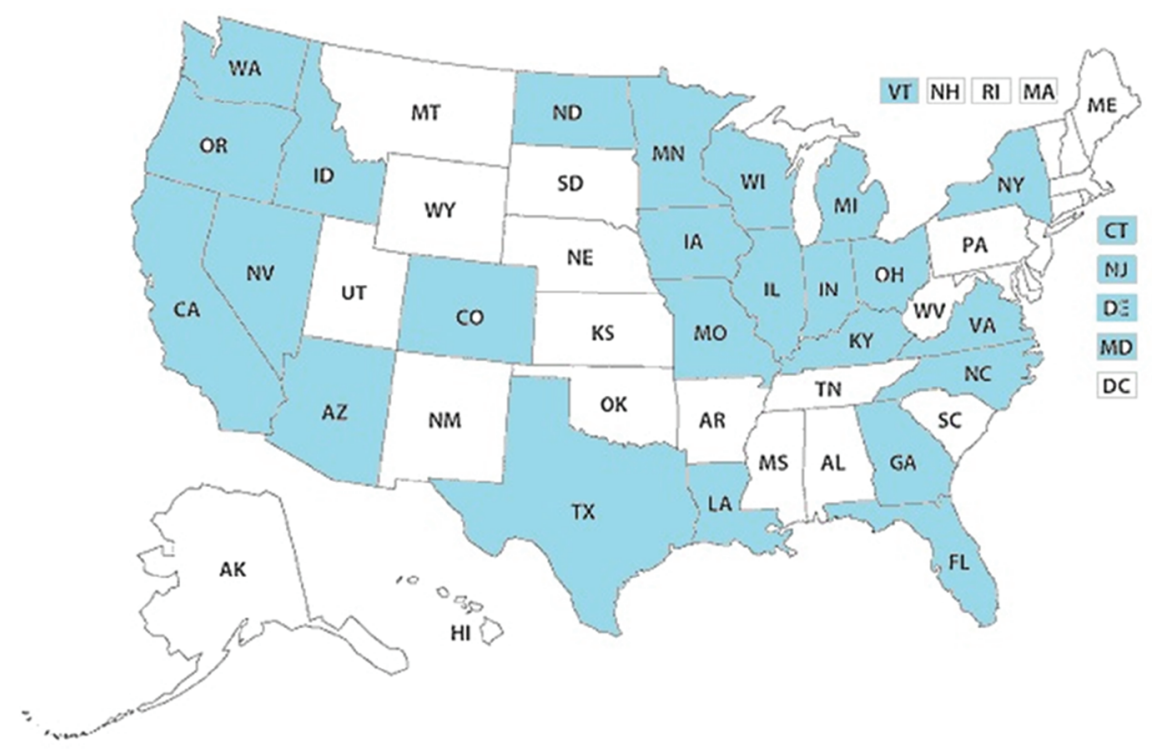

Figure 1: Geographic coverage of sample states (shaded states are included in the sample).

index (CPI). All dollar values are expressed in terms of per capita and converted to real values (using 1982-1984 as the base year). Financial data was matched with demographic information. This study focuses on several different categories of public goods and services including administration, corrections, elementary education, higher education, health and human services, highways, police and fire protection, sanitation and utilities. ${ }^{9}$

Table 1 displays summary statistics. The dataset contains 309 observations. The descriptive statistics indicate considerable variation in EDI spending and spending on different categories of public goods and services across states. ${ }^{10}$

9 Following Case, Hines and Rosen (1993), expenditures on health and human services are the sum of health and hospital spending and public welfare expenditures.

10 Part of the variation, however, might be induced by differences in state reporting. States may only report EDI spending for some programs but not all. Some states report both state and local incentives, while some others report only state-level incentives. Given that states offer the most tax incentives, which are the most frequently used, and do contribute to some local incentives as well, the omission of some local incentives in the database is less likely to be a serious issue. In addition, sate reporting also tends to improve over time, with more entries in the data in more recent years. Under-reporting is more of an issue for smaller subsidy deals than larger ones. Mega-sized incentives deals receive national attention and are, thus, more likely to be included in the database. 
Table 1: Summary statistics (Obs $=309)$.

\begin{tabular}{lrrrr}
\hline Variables & Mean & Std. Dev. & Min & Max \\
\hline EDI (\%) & 0.24 & 0.34 & 0.002 & 1.91 \\
In_income (\$) & 11.38 & 1.08 & 9.00 & 13.54 \\
In_revenue (\$) & 8.29 & 0.17 & 7.88 & 8.83 \\
In_density & 4.81 & 1.18 & 2.20 & 6.91 \\
Under15 (\%) & 20.48 & 1.20 & 17.02 & 23.39 \\
Above 65 (\%) & 12.82 & 1.53 & 9.61 & 18.14 \\
Administration (\%) & 3.80 & 0.73 & 2.50 & 5.99 \\
Corrections (\%) & 2.32 & 0.61 & 0.75 & 3.80 \\
Elementary education (\%) & 18.27 & 2.16 & 13.88 & 24.85 \\
Higher education (\%) & 7.61 & 2.15 & 3.15 & 12.53 \\
Health \& human services (\%) & 16.08 & 2.64 & 10.03 & 23.15 \\
Police \& fire protection (\%) & 4.10 & 0.93 & 2.26 & 6.94 \\
Highways (\%) & 2.84 & 0.91 & 1.25 & 6.11 \\
Sanitation (\%) & 1.00 & 0.29 & 0.32 & 1.70 \\
Utilities (\%) & 3.60 & 1.37 & 1.40 & 7.44 \\
\hline
\end{tabular}

Sources: Incentive data are from Subsidy Tracker database. Data on demographic characteristics are from Bureau of the Census. Personal Income data are drawn from the Bureau of Economic Analysis and the rest government finance data are from Census historical database.

Notes: (1) All dollar figures have been converted to real values, deflated by CPI (1982-84=100). (2) All dollar values are on a per capita basis. (3) Population density is in persons per square mile.

A closer examination of my sample reveals that Kentucky in 1998 spent the most on incentives as a percentage of direct expenditures, about 1.2\%; while EDI spending in Virginia in 1999 has the smallest proportion, close to 0. Among different categories of public goods and services, elementary education and higher education together account for a quarter of total expenditures, while health and human services make up about $16 \%$. Police and fire protection and administration each reaches about 4 percent, whereas utilities, highways and corrections account for 3.6 percent, 2.8 percent and 2.3 percent, respectively.

\section{Regression Model}

\subsection{Baseline Model}

Following the spirit of Case, Hines and Rosen (1993), the baseline model with all variables in levels is specified as follows:

$$
y_{i t}=\beta_{0}+\beta_{1} \operatorname{EDI}_{i t}+\beta_{2} x_{i t}+\delta_{i}+\mu_{t}+v_{i t},
$$


where $y_{i t}$ is a category of public expenditures as a percentage of total expenditures for state $i$ in year $t, \mathrm{EDI}_{i t}$ is EDI spending as a percentage of total expenditures and $x_{i t}$ is own state characteristics The conditioning variables $\left(x_{i t}\right)$ include total revenue (i.e., federal grant or federal intergovernmental revenue and own source revenue), state personal income, population density and percentage of young and elder population. ${ }^{11}$ Total revenue and income measure resources are available to state and local governments, while population density captures economies or diseconomies of scale in public goods provision. Demographic characteristics are included to account for the demand for public goods from specific demographic groups. State and year fixed effects are included to control for unobserved factors that do not change over time and macro shocks that affect all states in the same time period.

\subsection{Dynamic Panel - GMM Estimation}

Public expenditures, like many other economic variables, are dynamic in nature: spending decisions are likely to follow historical patterns and are influenced by contemporaneous factors. Following Kelejian and Robinson (1993), Redoano (2007) and Zhuang (2013), I include a one-year lag of dependent variables in the baseline model eq. [1] in order to accommodate the sluggish adjustments in public expenditures over time. Expenditures on public goods and services for state $i$ in year $t$ are then modeled as follows:

$$
y_{i t}=\beta_{0}+\beta_{1} y_{i t-1}+\beta_{2} \mathrm{EDI}_{i t}+\beta_{3} x_{i t}+\delta_{i}+\mu_{t}+v_{i t},
$$

Introducing lagged dependent variables, however, brings estimation challenges as illustrated below. To address these concerns, Arellano and Bond (1991) propose the GMM estimator. First, the GMM estimator gets rid of state fixed effects through differencing. Second, lagged endogenous variables in the level form and lagged exogenous variables in the differenced form serve as instruments. At last, specification tests are performed to check the validity of instruments. A problem with first differencing the model is that it magnifies gaps in data for an unbalanced panel. To mitigate the problem, I adopt forward orthogonal deviation to transform my data instead of using first differencing (Roodman 2009).

A potential problem with difference GMM estimator is that lagged independent variables can be poor instruments when they do not change much over time. Because this might pose a problem, I use the system GMM developed by

11 Total revenue, state personal income and population density are taken in log forms. 
Blundell and Bond (1998) for estimation. It helps to address the aforementioned problem with difference GMM by providing more moment conditions available from the level equation. Following Blundell and Bond (1998) the level eq. [2] is incorporated in the first-differenced GMM. Variables in the level equation are instrumented with their own differences.

\subsubsection{Estimation Concerns}

To see estimation challenges in a dynamic panel as laid out in eq. [2], the model is written in a more generic form below:

$$
\begin{gathered}
y_{i t}=\alpha y_{i t-1}+\beta^{\prime} x_{i t}+\varepsilon_{i t}, \\
\varepsilon_{i t}=\delta_{i}+\mu_{t}+v_{i t}, \quad \text { for } i=1,2, \ldots, N, t=2, \ldots, T .,
\end{gathered}
$$

We can easily tell that lagged dependent variable $y_{i t-1}$ is correlated with $\delta_{i}$ in the error term. This endogeneity causes OLS (Ordinary Least Squares) estimator to be biased and inconsistent. Further, this problem cannot be circumvented with 2SLS (Two Stage Least Squares) or panel fixed effects estimator (Nickell 1981; Roodman 2009). The GMM estimator proposed by Arellano and Bond (1991) is a standard way to address these concerns.

\subsubsection{First-Differenced GMM: Arellano and Bond (1991)}

The GMM estimator starts with first differencing the model to remove state fixed effects. The transformed model is estimated using lagged levels of the dependent variable and endogenous variables, as well as differences of exogenous variables as instruments. The first differenced model and moment conditions are listed as below.

$$
\begin{gathered}
\Delta y_{i t}=\alpha \Delta y_{i t-1}+\beta^{\prime} \Delta x_{i t}+\Delta \varepsilon_{i t}, \\
\Delta \varepsilon_{i t}=\left(\delta_{i}-\delta_{i}\right)+\Delta \mu_{t}+\Delta v_{i t}, \text { for } i=1,2, \ldots, N \text { and } t=2, \ldots, T, \\
E\left(y_{i t-s} \Delta \varepsilon_{i t}\right)=0 \text { for } t=3,4, \ldots, T \text { and } s \geq 2, \\
E\left(\Delta x_{i t-s} \Delta \varepsilon_{i t}\right)=0 \text { for } t=3,4, \ldots, T \text { and } s \geq 2,
\end{gathered}
$$

\subsubsection{Forward Orthogonal Deviation Transformation - Adapted to an Unbalanced Panel}

First differencing, however, shrinks the data set and amplifies gaps in an unbalanced panel. If $y_{i t}$ is missing, for example, then both $\Delta y_{i t}$ and $\Delta y_{i t+1}$ are 
missing in the first differenced transformed data. Alternative transformations, forward orthogonal deviations or orthogonal deviations help to mitigate the problem (Arellano and Bover 1995). In contrast to the first differencing transformation, which deducts observation from the last period from the present one, the forward orthogonal deviation transformation subtracts the average of all future values from the present one (Roodman 2009). Thus, the forward orthogonal deviation transformation only discards the last observation for each group, which minimizes data loss. ${ }^{12}$

Further, lagged observations are valid instruments since they do not enter the formula. A recent simulation study by Hayakawa (2009) shows that the GMM estimator transformed by forward orthogonal deviation tends to work better than the one transformed by first differencing. Given that my panel is unbalanced with gaps, I adopt the forward orthogonal deviation transformation to preserve observations. ${ }^{13}$

\subsubsection{Specification Tests for GMM Estimators: AR (1), AR (2) and Sargan/Hansen Tests}

The consistency of the difference GMM estimator depends critically on the validity of the moment conditions listed in eqs [5] and [6] and the lack of second-order serial correlation in the error terms. The Sargan/Hansen test is used to examine the validity of instruments. The null hypothesis is that the instruments are exogenous as a group. As a result, a higher $p$-value of the Sargan/Hansen statistic is preferred.

The other important diagnostic is the AR test for autocorrelation of the residuals. The consistency of the GMM estimator relies on the lack of second-order serial correlation. By construction, the residuals of the first differenced equation should possess serial correlation. Accordingly, the null is always rejected for the AR (1) test. For instruments to be valid, differenced residuals should not show significant second-order serial correlation. Accordingly, a high reported $p$-value in AR (2) test indicates that the moment conditions are valid. If the AR (2) statistic is significant, longer lags need to be used.

12 Recent empirical works employing this transformation include Baum, Checherita-Westphal, and Rother (2013) and Dieleman, Graves, and Hanlon (2013).

13 Please refer to Roodman (2009) for mathematical representation. 


\subsection{Capturing Lagged Effects of EDI}

Lastly, I include lagged values of incentives expenditures to capture possible delayed effects of incentives to allow time for reactions to occur. Specifically, the dynamic panel model in eq. [2] is modified as follows:

$$
y_{i t}=\beta_{0}+\beta_{1} y_{i t-1}+\beta_{2} \mathrm{EDI}_{i t}+\beta_{3} \mathrm{EDI}_{i t-s}+\beta_{4} x_{i t}+\delta_{i}+\mu_{t}+v_{i t}, \text { where } s=1 \text { or } 2
$$

\section{Results}

Basic regression results of eq. [7] are summarized in Table 2 with each column representing a specific category of public goods. OLS, FE (Fixed Effects) and system GMM estimation have been performed. As discussed in the literature (Roodman 2009), the lagged dependent variable was positively correlated with the error, which biases $\beta_{1}$, the coefficient associated with $y_{i t-1}$, upward for OLS estimation; whereas the estimate of $\beta_{1}$ is biased downward due to the negative sign in front of the within-group transformed error from the fixed effects regression. Therefore, a reliable estimate should lie in between the two values, which serves as a useful check. ${ }^{14}$

Coefficient estimates are generated using a one-step GMM. ${ }^{15}$ The second lag or more of endogenous variables (lagged public expenditures, $y_{i t-1}$ ) are selected as instruments while all lags for exogenous variables (total revenue, EDI, population density and percentages of old as well as young population) serve as instruments. ${ }^{16}$ Hansen test statistics are presented to examine the validity of the instruments. The reported AR (1), AR (2) and Hansen results support the validity of selected instruments.

In general, the results indicate that incentives expenditures are not contemporaneously correlated with public expenditures at the state level. ${ }^{17}$ They

14 This condition is met with my results, but due to space limitation, only GMM results are presented here. Fixed effects estimation results are reported in Table 8. FE estimation results are consistent with those from system GMM estimation. Generally speaking, the coefficients of EDI have the same directions, but are smaller in magnitudes and insignificant in the case of corrections, higher education and health and human services.

15 For applied work using the one-step GMM estimator, please refer to Arai, Kinnwall, and Thoursie (2004), Falk (2006), Huang, Hwang, and Yao (2006), etc.

16 Given that public expenditures may affect economic growth, hence personal income, personal income is also treated as endogenous in all regressions.

17 Results from Table 3 which exclude contemporaneous EDI spending remain qualitatively similar to those in Table 2. 


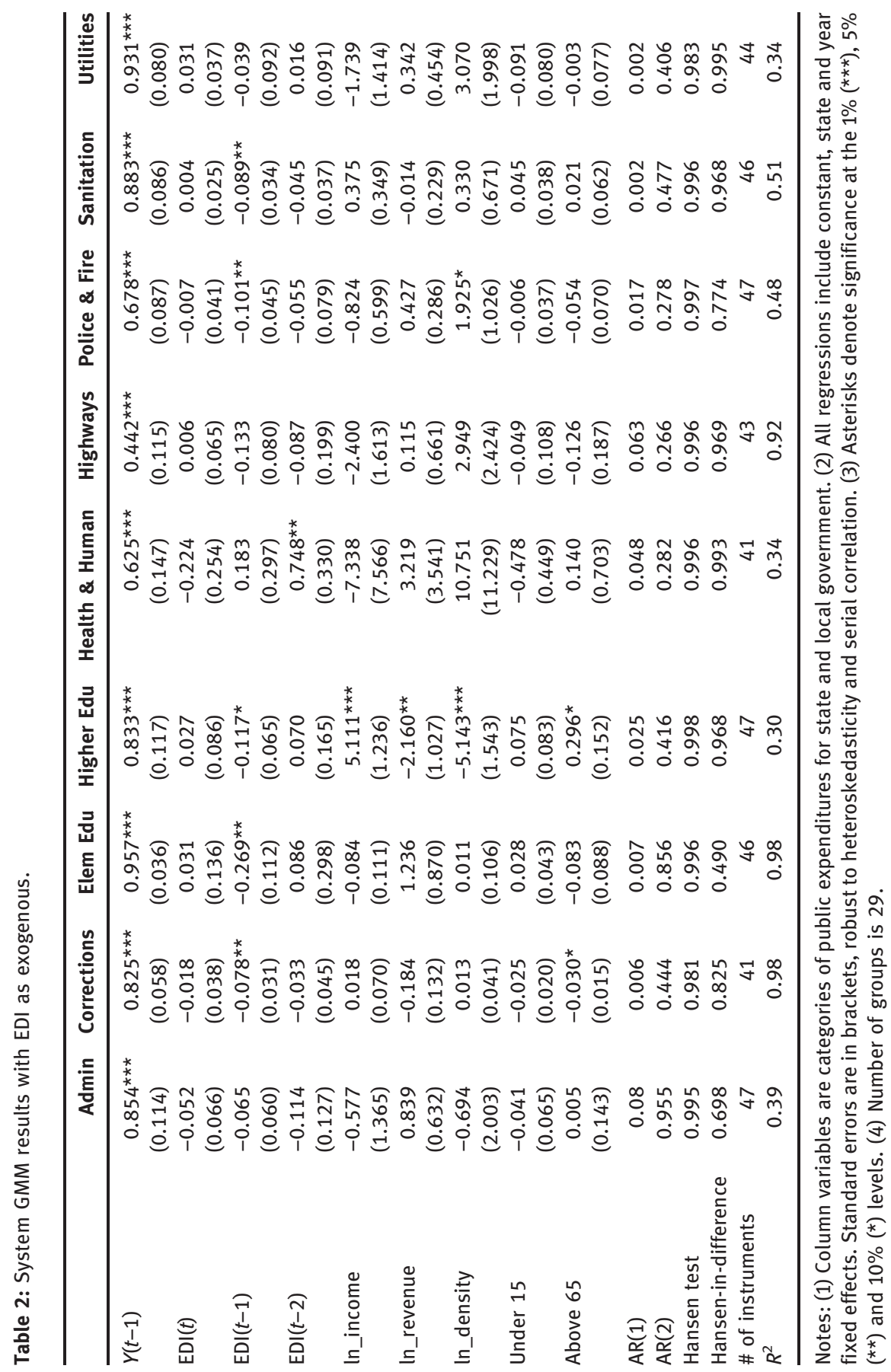




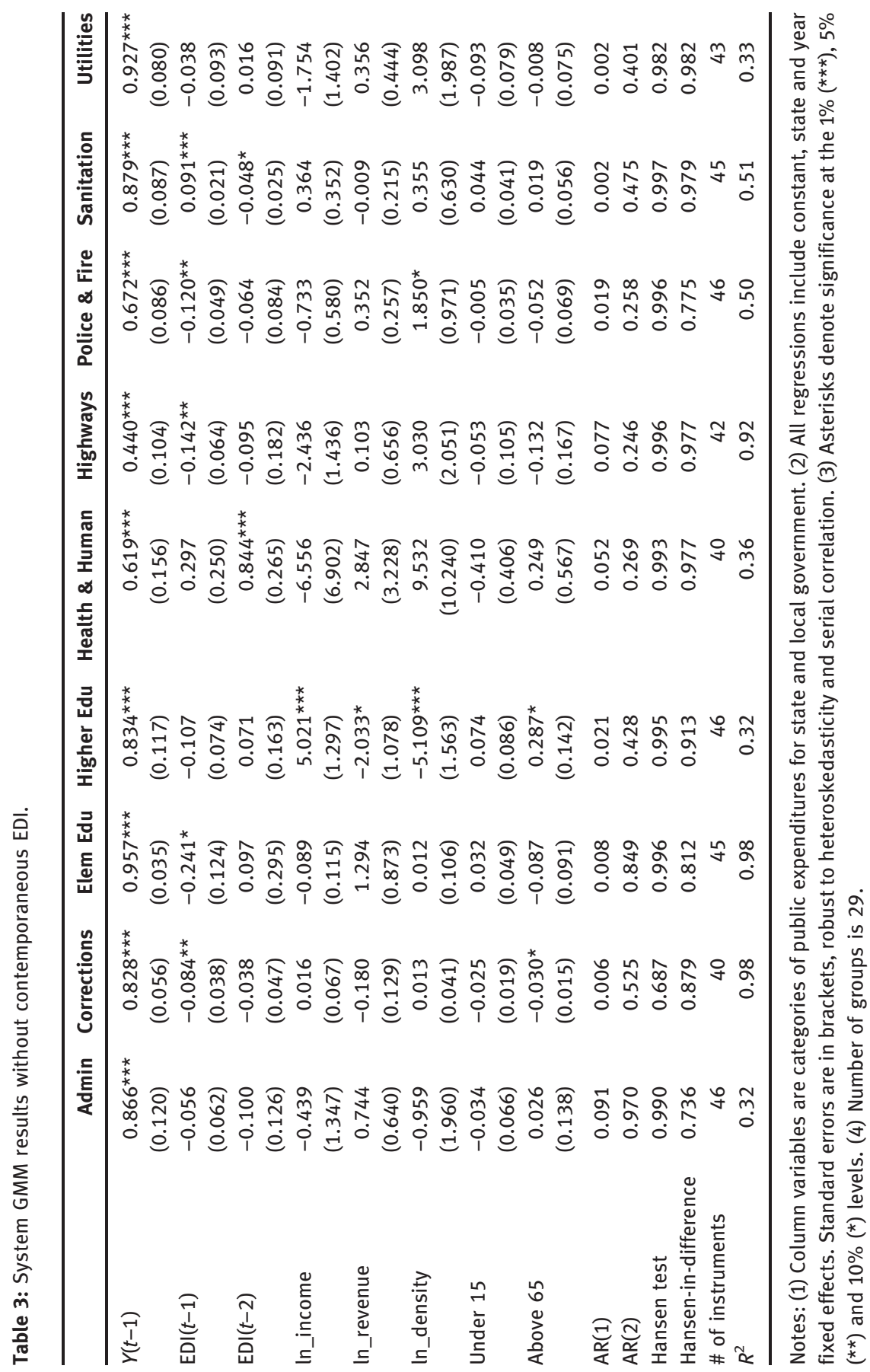


are, however, negatively correlated with categories of public expenditures after one year, and the relationship is statistically significant at conventional levels. There is evidence of decreases in percentages of expenditures on corrections, elementary education, higher education, police and fire protection and sanitation associated with EDI expenditures. The proportion of total expenditures on health and human services, on the other hand, is found to be positively associated with EDI expenditures after two years.

It is worth noting that most of the decreases in spending do not occur contemporaneously, which seems to indicate that at least in the immediate future EDI do not contribute to an increased proportion of spending on some productive public goods and services. Patrick (2012) finds that increases in county-level public expenditures associated with the opening of a million dollar plant result from borrowing rather than growth. Accordingly, the ability to borrow helps to delay spending cuts in the immediate period. In addition, the delayed effects of EDI could also be partially attributable to the underlying EDI data, in which values are aggregates of contemporaneous and future incentives. $^{18}$

The coefficients associated with incentives spending are not only statistically significant, but also have potentially huge economic effects. Take elementary education for example. A one percentage point increase in EDI spending is associated with 0.269 percentage point decrease in operating expenditures on elementary education a year later. Given that elementary education accounts for $18.27 \%$ of the average state's total expenditures, this implies a $1.47 \%(0.269 /$ $\left.18.27^{\star} 100\right)$ drop in one year.

Demographic characteristics can influence the composition of public spending to the extent that they determine the needs and preferences of population for public goods. The inclusion of population density provides information about scale economies and potential congestion effects in the provision of public

18 In the first robustness check in Section 6, current EDI spending is treated as endogenous, which is instrumented by lagged EDI spending. Some readers might suspect the validity of instruments given some past EDI spending incorporates current EDI spending information as well. Please note that Hansen over-identification test helps to address this concern, which tests the validity of instruments as a group. Hansen test results have been reported at the bottom of each table, which suggests that instruments are exogenous. Conceptually, state and year fixed effects have accounted for differences in public expenditures, which makes the remaining correlation (if any) between EDI spending and error term less severe. In addition, the incentives spending used as instruments is lagged by at least two periods which suggests that any remaining correlation should be small, which is likely to be especially true when both dependent and independent variables are expressed as a percentage of total expenditures. This explains why the statistical tests indicate instruments are exogenous. 
goods. The estimated coefficients for population density are mixed. Negative coefficients indicate economies of scale while positive coefficients indicate diseconomies of scale. My results are similar to those of Ermini and Santolini (2010) and Silva, Veiga, and Portela (2011). The effect of the share of elder population (above 65) varies with the category of public goods. The proportion of population below 15 is mostly not correlated with public goods provision. ${ }^{19}$

\section{Robustness Checks ${ }^{20}$}

A number of robustness checks have been performed. First, the basic model is estimated using system GMM where EDI are treated as endogenous. Because the extent to which states use EDI might depend on other unobservable factors which influence public spending choices, the incentives variable may be correlated with error term. For example, the pressure to fund public expenditures is likely to cause the state to be more or less aggressive in offering incentives. ${ }^{21}$ To deal with this potential endogeneity problem, I instrument EDI $_{i t}$ with its lags. Conceptually, further lags of incentives spending in the past are likely to be correlated with current incentives spending but not current public expenditures. The validity of instruments has been tested and shown by AR (1), AR (2) and Hansen tests, the results of which are presented in Table 4. Compared with the

19 When omitting personal income, the share of young population is negatively associated with expenditures on higher education, sanitation and highways, while positively associated with health and human services expenditures. This makes sense as higher education expenditures are devoted to population aged 17 years or above. Additionally, younger people generally live with their parents. Hence a greater percentage of young population implies fewer households, which reduces spending on sanitation and utilities. Similar reasoning applies to highways expenditures: a higher percentage of young people implies fewer drivers on the road, and consequently less need to maintain/expand highways. A larger proportion of young people, however, can be expected to increase expenditures on health and hospitals as well as public welfare.

20 I also estimate an alternative model to investigate if the changes in incentives expenditures have an impact on changes in expenditures on public goods. The first differenced model, however, essentially looks at contemporaneous effects of incentives on the provision of public goods. It is, therefore, not surprising that most of the predicted impacts are insignificant, which reflects the time needed for EDI to impact spending.

21 According to the Economist, 'The cash crunch that followed the downturn led some states to spend more on economic development in order to lure businesses. It has led others to save precious funds by tightening economic development budgets.' Sweet land of subsidy: http:// www.economist.com/news/unitedstates/21576669-downturn-has-forced-states-be-savvier-andmore-careful-about-providing-tax. 


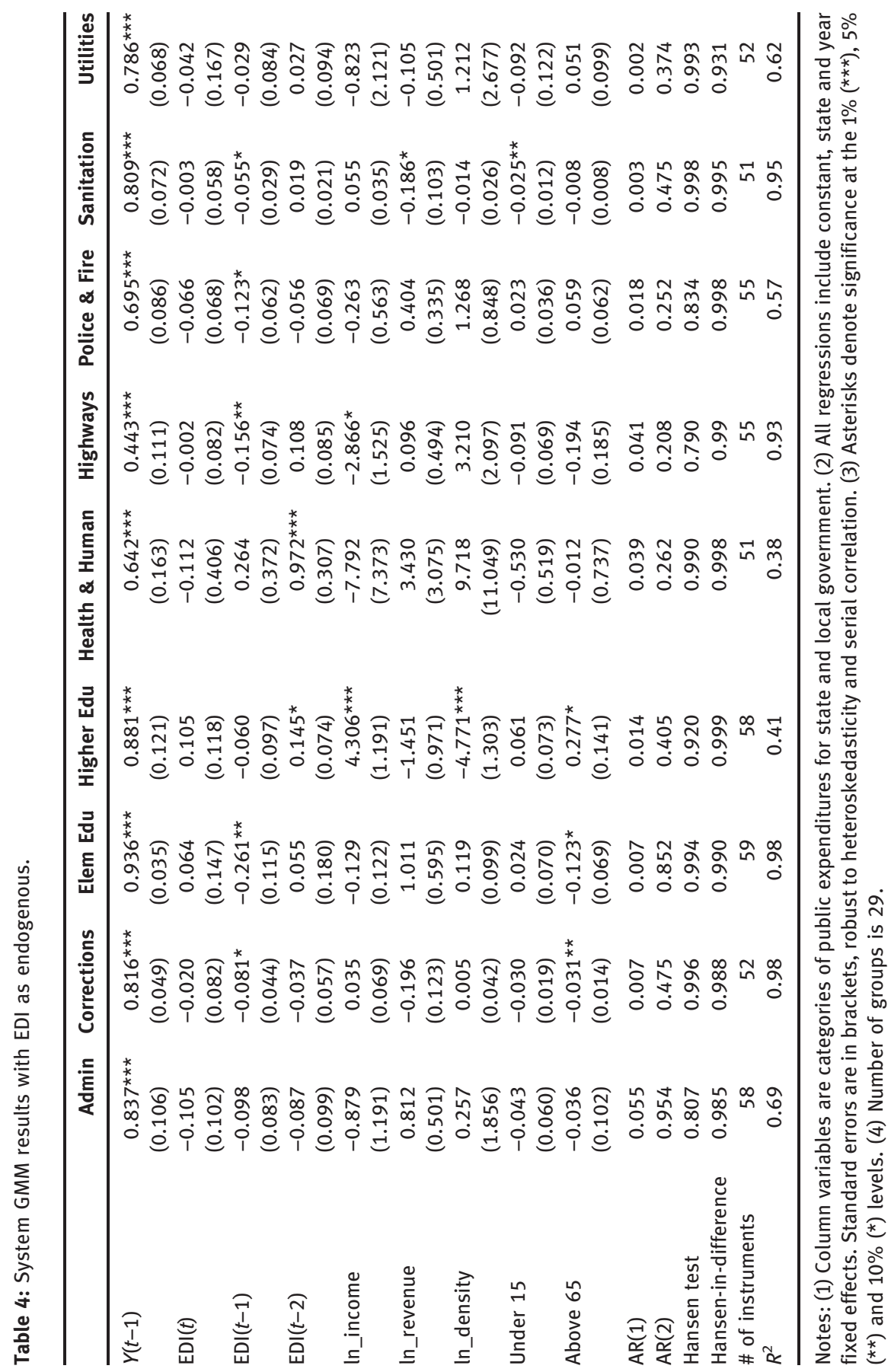


results in Table 2, the estimated negative correlation between EDI and public expenditures is strengthened in half of the cases: not only do the magnitudes of estimated coefficients become larger, the significant level also increases. The estimated coefficient on health and human services increases from 0.748 to 0.972 and the significance level increases to $1 \%$. For police and fire protection and sanitation, the significance level of estimated coefficients also increases to $5 \%$. EDI spending is now negatively correlated with highways expenditures after a year as well. Overall, this suggests that the effects of incentives may be underestimated if potential endogeneity is ignored. Estimates related to demographic variables are similar to the baseline estimates except that the percentage of elder population is also found to be negatively associated with elementary education spending: a one percentage point increase in elder population is associated with 0.12 percentage point decrease in the proportion of elementary education spending out of total expenditures.

To avoid the confounding effects of the recent financial crisis, a second robustness check is done by estimating the model excluding data for years 2007 and 2008. Results, which are displayed in Table 5, are qualitatively similar and the significance level increases for most coefficient estimates. In addition to the above-mentioned public goods, administration has also been found to be negatively correlated with EDI spending. In particular, a one percentage point increase in EDI spending (as a fraction of total expenditures) is associated with 0.376 percentage point decrease in administration spending two years later. Coefficient estimates also increase in magnitude for elementary education and health and human services.

A third robustness check is done to check if a particular state or certain states are driving the results. More specifically, Colorado and New York are excluded from the baseline model. Out of the total EDI in the sample, Colorado accounts for about $0.3 \%$, and New York accounts for about $8 \%$. Results are presented in Tables 6 and 7 for Colorado and New York, respectively. Again, coefficient estimates are qualitatively the same as in the previous estimation (Table 2). The magnitudes and significant levels are similar as well.

\section{Conclusion}

EDI are widely used by state and local governments as a tool to lure investment, create jobs and ultimately induce economic growth. Despite sizeable incentives offered, very few states effectively evaluate the EDI programs offered (Pew Center Report 2012). The prominence of business incentives in public policy 


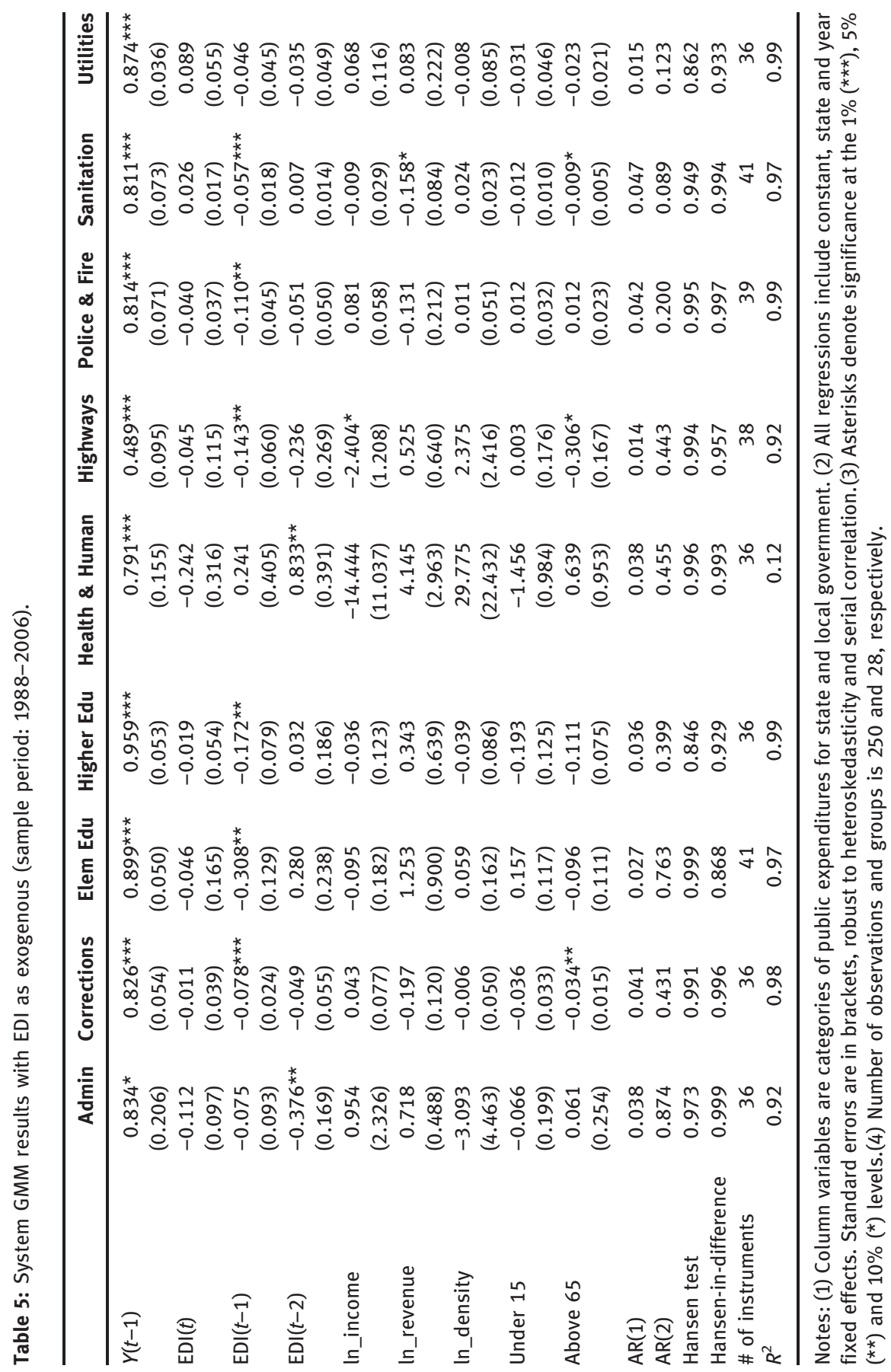




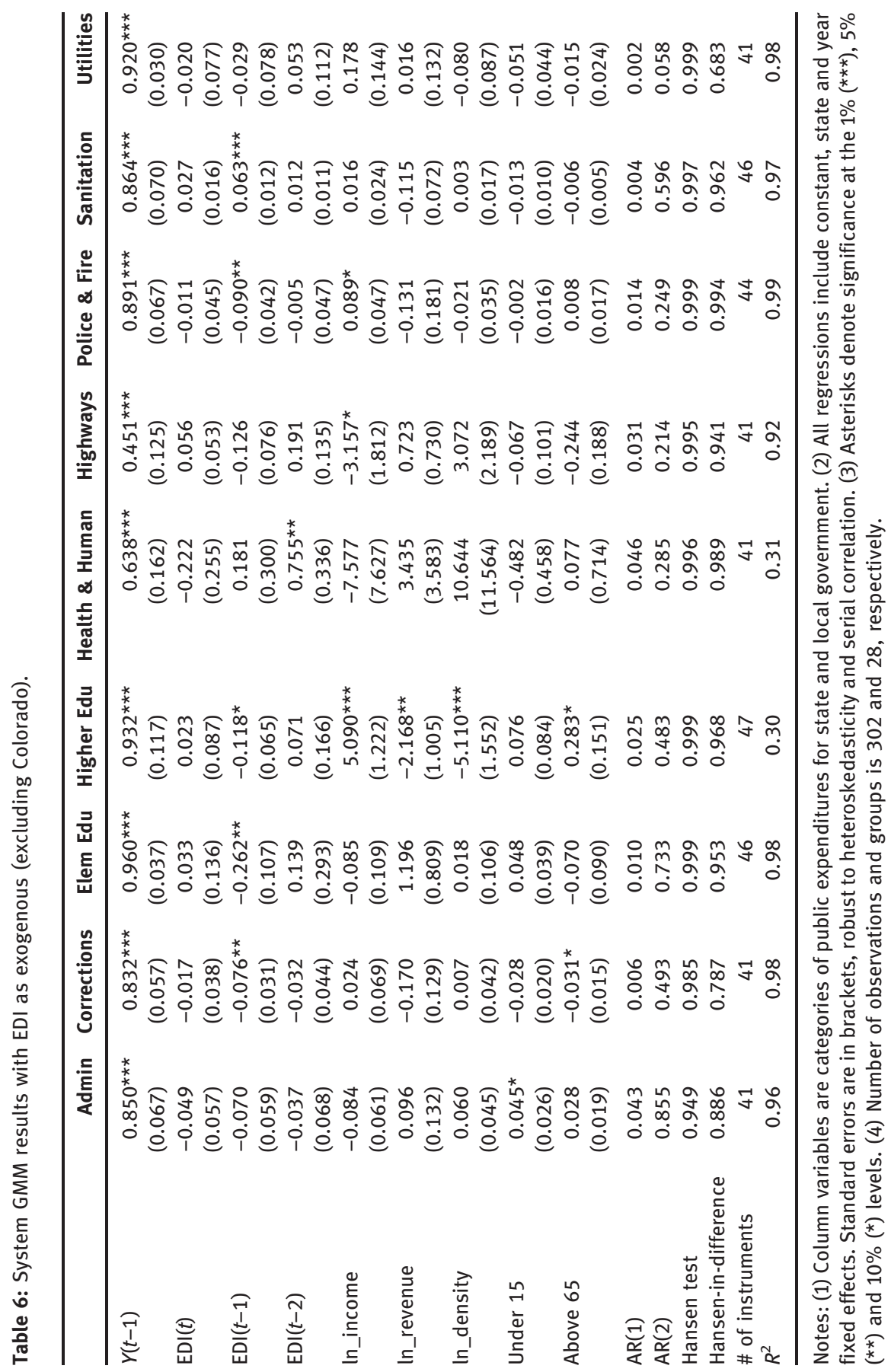




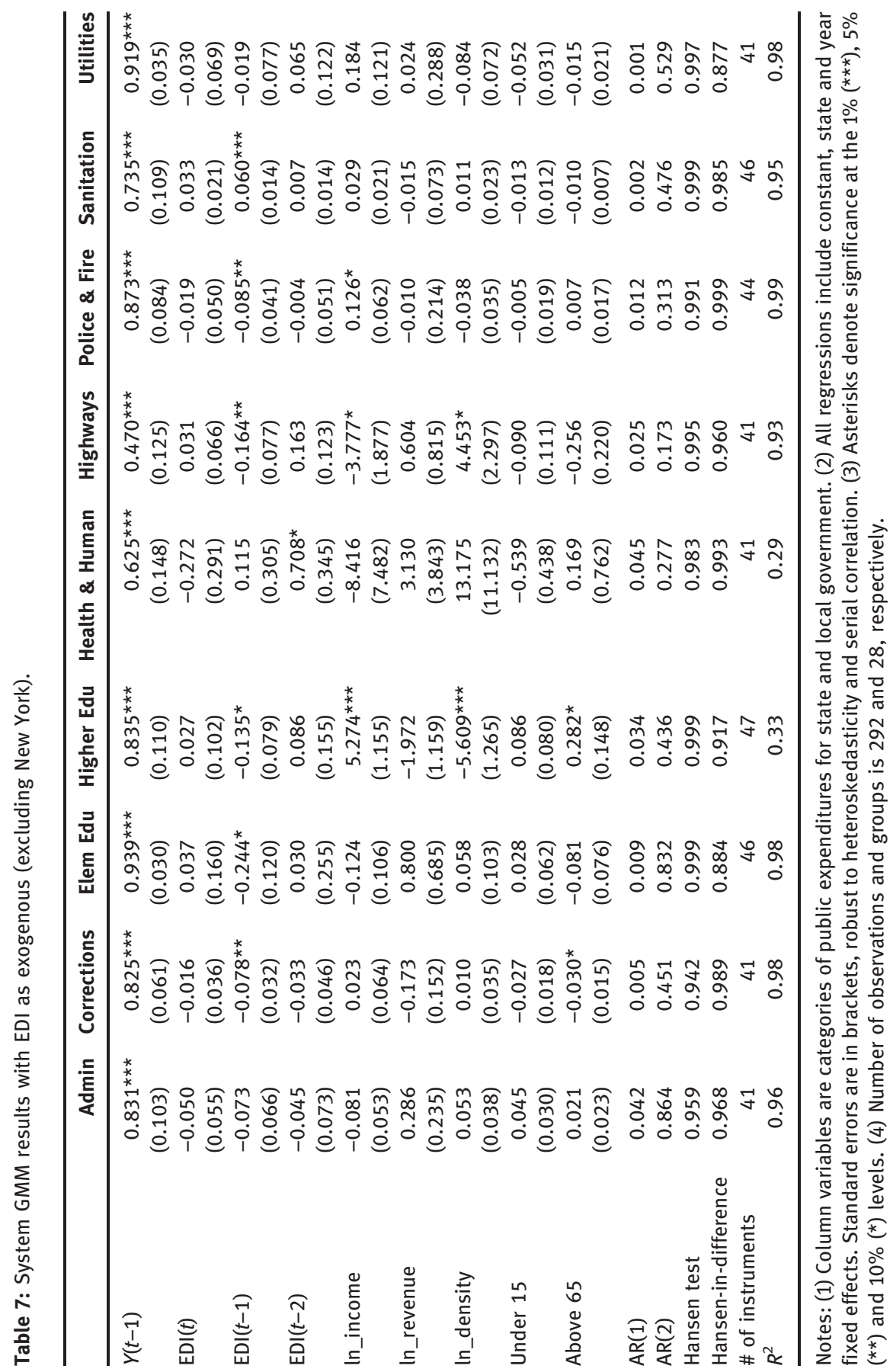


debates on economic development has led to extensive theoretical and empirical research. Opponents of EDI argue that incentives come at the expense of spending on basic public goods, which could in turn retard growth. Most empirical research to date, however, has focused on evaluating the employment and investment/ growth effects of a particular incentive program in a single geographic area.

This paper takes a novel approach by investigating whether EDI spending crowds out spending on other public goods and services at the state level. With the benefit of a national database of EDI, dynamic panel data analysis is implemented. Estimates using system GMM estimator controlling for the dynamic nature of state spending as well as possible lagged effects of incentives show that public expenditures are negatively associated with EDI use. In particular, the main findings indicate that incentives expenditures are associated with decreases in expenditures on productive public goods such as education and highways as well as corrections, police and fire protection and sanitation. ${ }^{22}$ EDI spending has also been found to be positively correlated with spending health and human services. Empirical evidence shows that incentives do not seem to contribute to increased share of spending on productive public goods and services in the immediate future. This, to some extent, contradicts the claims that incentives lead to beneficial growth in the economy. Or if growth occurs, it does not seem to expand spending on productive public goods and services. Policymakers need to consider "unintended" side effects if EDI spending does crowd out expenditures on other growth-enhancing public goods.

Despite providing more comprehensive and detailed information compared with data used in previous research, the Subsidy Tracker database has limitations. In addition, out of sample extrapolation should be done with caution because the sample of states is not exhaustive even though a good portion of U.S. population and economic activity is represented. In times of fiscal stress, it is of paramount importance to understand what states are giving up especially given the close link between public services and economic growth (Helms 1985; Mofidi and Stone 1990; Miller and Russek 1997). My findings echo the long-standing criticism of EDI spending (Burstein and Rolnick 1995; Fisher and Peters 2004). For policymakers who care about long-term economic growth, the extensive use of EDI is questionable.

22 It is possible that reduction in unemployment contributes to less crime, which in turn leads to the decreased share of spending on corrections. But the increased share of spending on health and human services, driven mainly by increased share of spending on welfare programs, seems to weaken that possibility. In addition, state prison overcrowding and high recidivism rates throughout the sample period further undermine that story. Nevertheless, the specific channels causing the decreased share of spending on certain public goods and services are left for future research. 


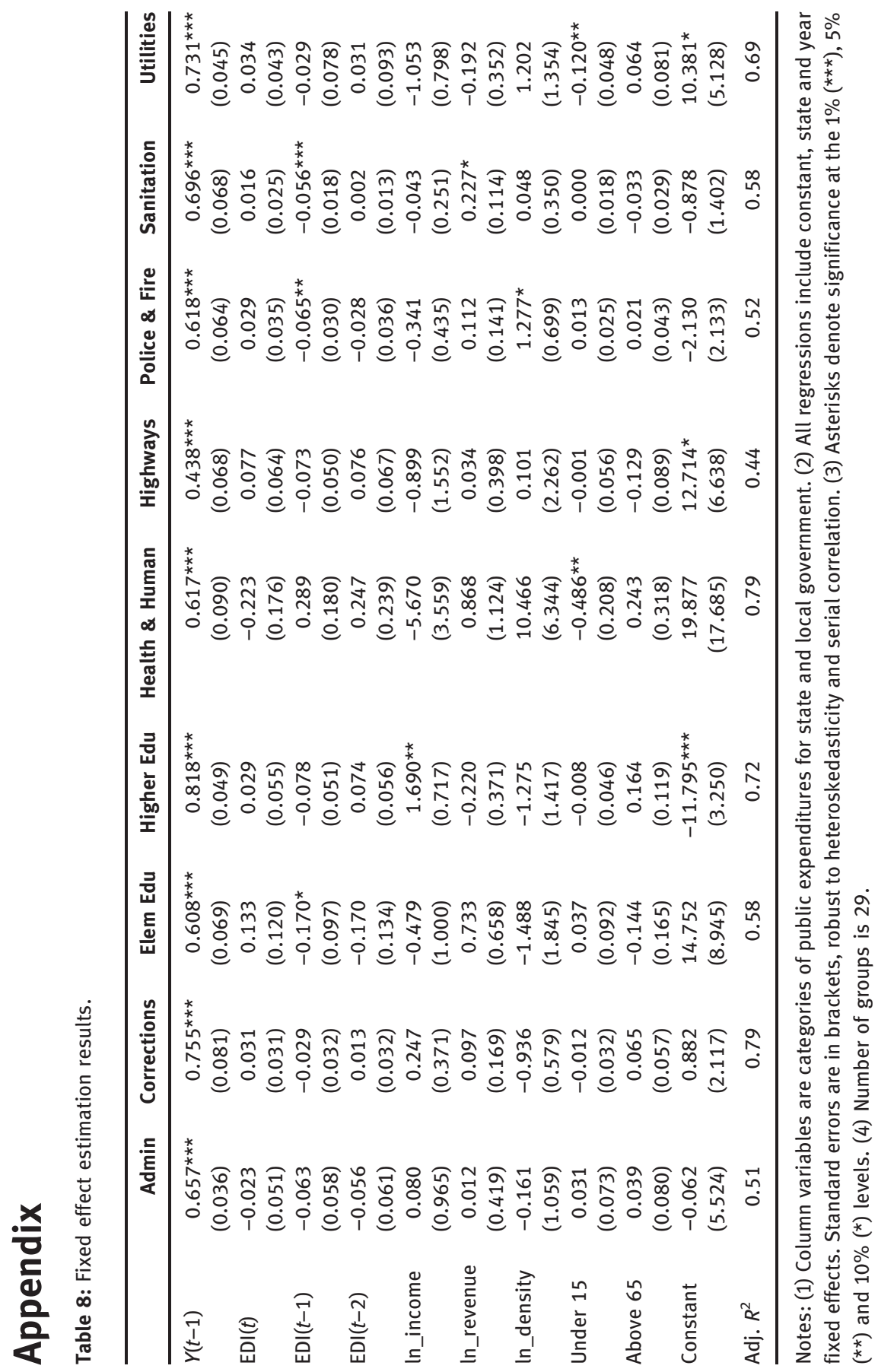


Table 9: List of states in the sample.

\begin{tabular}{l} 
Arizona \\
California \\
Colorado \\
Connecticut \\
Delaware \\
Florida \\
Georgia \\
Idaho \\
Illinois \\
Indiana \\
lowa \\
Kentucky \\
Louisiana \\
Maryland \\
Michigan \\
Minnesota \\
Missouri \\
Nevada \\
New Jersey \\
New York \\
North Carolina \\
North Dakota \\
Ohio \\
Oregon \\
Texas \\
Vermont \\
Virginia \\
Washington \\
Wisconsin \\
\hline
\end{tabular}

\section{References}

Arai, M., M. Kinnwall, and P. S. Thoursie. 2004. "Cyclical and Causal Patterns of Inflation and GDP Growth.” Applied Economics 36 (15):1705-15.

Arellano, M., and S. Bond. 1991. "Some Tests of Specification for Panel Data: Monte Carlo Evidence and an Application to Employment Equations." The Review of Economic Studies 58 (2):277-97.

Arellano, M., and O. Bover. 1995. "Another Look at the Instrumental Variable Estimation of Error-Components Models." Journal of Econometrics 68 (1):29-51.

Bartik, T. J. 1991. Who Benefits from State and Local Economic Development Policy? Kalamazoo, MI: W. E. Upjohn Institute for Employment Research Press.

Bartik, T. J. 1994. “Jobs, Productivity, and Local Economic Development: What Implications Does Economic Research Have for the Role of Government?"National Tax Journal 47 (4):847-61. 
Bartik, T. J., and G. Erickcek. 2012. Simulating the effects of Michigan's MEGA tax credit program on job creation and fiscal benefits. Upjohn Institute Working Paper 12-185. Kalamazoo, MI: W.E. Upjohn Institute for Employment Research.

Baum, A., C. Checherita-Westphal, and P. Rother. 2013. "Debt and Growth: New Evidence for the Euro Area." Journal of International Money and Finance 32:809-21.

Blundell, R., and S. Bond. 1998. "Initial Conditions and Moment Restrictions in Dynamic Panel Data Models." Journal of Econometrics 87 (1):115-43.

Burstein, M., and A. Rolnick. 1995. Congress should end the economic war among the states. The 1994 Annual Report of the Minneapolis Federal Reserve Bank.

Case, A. C., H. S. Rosen, and J. R. Hines Jr. 1993. "Budget Spillovers and Fiscal Policy Interdependence: Evidence from the States." Journal of Public Economics 52 (3):285-307.

Calcagno, P. T., and F. Hefner. 2009. "South Carolina's Tax Incentives: Costly, Inefficient and Distortionary." Ch 7:131-47.

De Bartolome, C. A. M., and Spiegel, M. M. 1997. "Does State Economic Development Spending Increase Manufacturing Employment?" Journal of Urban Economics 41:153-75.

Dieleman, J. L., C. M. Graves, and M. Hanlon. 2013. "The Fungibility of Health Aid: Reconsidering the Reconsidered." Journal of Development Studies 49 (12):1755-62.

Ermini, B., and R. Santolini. 2010. "Local Expenditure Interaction in Italian Municipalities: Do Local Council Partnerships Make a Difference?" Local Government Studies 36 (5):655-77.

Falk, M. 2006. What drives business Research and Development (R\&D) intensity across Organization for Economic Co-operation and Development (OECD) countries? Applied Economics 38 (5):533-47.

Fisher, P. S., and A. H. Peters. 1997. Tax and Spending Incentives and Enterprise Zones. New England Economic Review.

Fisher, R. C. 1997. "The Effects of State and Local Public Services on Economic Development." New England Economic Review 53-66.

Good Jobs First. 2013. "Subsidy Tracker.” http://www.goodjobsfirst.org/subsidytracker.

Goodman, D. J. 2003. “Are Economic Development Incentives Worth It? A Computable General Equilibrium Analysis of Pueblo, Colorado's Efforts to Attract Business. Journal of Regional Analysis and Policy 33 (1):43-56.

Gorin, D. 2008. “Economic Development Incentives: Research Approaches and Current Views." Federal Reserve Bulletin, (Oct).

Goss, E. P., and J. M. Phillips. 1997. "The Effect of State Economic Development Agency Spending on State Income and Employment Growth." Economic Development Quarterly 11 (1):88-96.

Greenstone, M., and E. Moretti. 2003. Bidding for Industrial Plants: Does Winning a 'Million Dollar Plant' Increase Welfare? (No. w9844). National Bureau of Economic Research.

Harpel, Ellen, "Good Jobs First and Subsidy Tracker 2.0". 07/02/2014: http://www.smartincen tives.org/blogs/blog/14754093-good-jobs-first-and-subsidy-tracker-2-0.

Hayakawa, K. 2009. "First Difference or Forward Orthogonal Deviations-Which Transformation Should be used in Dynamic Panel Data Models?: A Simulation Study." Economics Bulletin 29 (3):2008-17.

Helms, L. J. 1985. "The Effect of State and Local Taxes on Economic Growth: A Time Series-Cross Section Approach.” The Review of Economics and Statistics 67 (4):574-82.

Hoyt, W., C. Jepsen, and K. R. Troske 2007. An Examination of Incentives to Attract and Retain Businesses in Kentucky. 
Huang, B. N., M. J. Hwang, and C. W. Yang. 2008. "Causal Relationship between Energy Consumption and GDP Growth Revisited: A Dynamic Panel Data Approach.” Ecological Economics 67 (1):41-54.

Jansa, J., and V. Gray. The Politics and Economics of Corporate Subsidies in the 21st Century. Kelejian, H. H., and D. P. Robinson. 1993. "A Suggested Method of Estimation for Spatial Interdependent Models with Autocorrelated Errors, and an Application to a County Expenditure Model." Papers in Regional Science 72 (3):297-312.

Kenyon, D. A., A. H. Langley, and B. P. Paquin. 2012. "Property Tax Incentive Pitfalls. National Tax Journal 65 (4):1011-22.

Luger, M. I., and S. Bae. 2005. "The Effectiveness of State Business Tax Incentive Programs: The Case of North Carolina." Economic Development Quarterly 19 (4):327-45.

Miller, S. M., and F. S. Russek. 1997. "Fiscal Structures and Economic Growth: International Evidence." Economic Inquiry 35 (3):603-13.

Mofidi, A., and J. A. Stone. 1990. "Do State and Local Taxes Affect Economic Growth?" The Review of Economics and Statistics 72 (4):686-91.

Nickell, S. 1981. "Biases in Dynamic Models with Fixed Effects." Econometrica: Journal of the Econometric Society 49 (6):1417-26.

Ó hUallacháin, B., and M. A. Satterthwaite. 1992. "Sectoral Growth Patterns at the Metropolitan Level: An Evaluation of Economic Development Incentives.” Journal of Urban Economics 31 (1):25-58.

Patrick, C. E. 2012. Identifying the Local Economic Development Effects of Million Dollar Facilities. Working Paper. Georgia State University, Atlanta, GA.

Patrick, C. E. 2014. "Does Increasing Available Non-tax Economic Development Incentives Result in More Jobs? National Tax Journal 67 (2):51-386.

Peters, A., and P. Fisher. 2004. "The Failures of Economic Development Incentives." Journal of the American Planning Association 70 (1):27-37.

Pew Center Report. 2012. Evidence counts: evaluating state tax incentives for jobs and growth. The Pew Charitable Trusts, Washington, DC.

Redoano, M. 2007. Fiscal Interactions among European Countries: Does the EU matter?

Roodman, D. 2009. "How to do Xtabond2: An Introduction to Difference and System GMM in Stata." Stata Journal 9 (1):86.

Silva, H., L. G. Veiga, and M. Portela. 2011. Strategic Interaction in Local Fiscal Policy: Evidence from Portuguese Municipalities.

Story, Louise, Tiff Fehr, and Derek Watkins, United States of Subsidies, New York Times, 12/01/ 2012: http://www.nytimes.com/interactive/2012/12/01/us/government-incentives.html.

Wasylenko, M. 1997. "Taxation and Economic Development: The State of the Economic Literature." New England Economic Review issue Mar: 37-52.

Weiner, J. 2009. State business tax incentives: examining evidence of their effectiveness. New England Public Policy Center.

Wilson, J. D. 1999. Theories of tax competition. National Tax Journal 52 (2):269-304.

Wong, J. D., and M. T. Stiles. 2007. Strategic Analysis of Economic Development Expenditures by Kansas State Government and Five Surrounding State Governments: FY 1989-FY 2007. Kansas, Incorporated.

Yao, S. 2006. "On Economic Growth, FDI and Exports in China." Applied Economics 38 (3):339-51.

Zhuang, H. 2013. "The Effect of FDI on Local Education Expenditures: Evidence from the United States." Bulletin of Economic Research 65 (3):203-24. 